\title{
Silenciar a polissemia e invisibilizar os sujeitos: indagações ao discurso sobre a qualidade da educação'
}

\author{
Maria Teresa Esteban \\ Faculdade de Educação da Universidade Federal Fluminense, Brasil
}

Resumo

O artigo parte de diagnósticos sobre insucesso escolar, presentes em documentos oficiais produzidos em Portugal e pela União Européia, para discutir processos de silenciamento e produção de invisibilidade e de subalternidade que atravessam o discurso hegemônico sobre qualidade. Uma das idéias centrais na argumentação tecida no artigo é que legitimar uma única perspectiva epistemológica, um único universo de conhecimentos, um único conjunto de valores, é um modo de desqualificar o que se diferencia do padrão. A diferença cultural é sistematicamente enunciada como causa de fracasso escolar. A despeito dos discursos amparados na generalização conduzida pela universalização de parâmetros, os sujeitos que fracassam se apropriam de conhecimentos, bem como os produzem, e as escolas onde o insucesso se expressa são espaços de produção de conhecimentos múltiplos. Uma escola pública de qualidade para todos demanda conhecimentos sobre seu cotidiano, para além do que se pode perceber através da avaliação do desempenho.

Palavras-chave

Democratização; Avaliação; Fracasso escolar; Diferença cultural

Os homens modernos acreditaram que era possível "conter" o tempo dentro dos relógios, "capturar" o espaço dentro de um quadro e o movimento em um conjunto de "leis naturais" necessárias e eternas (Najmanovich).

A ampliação do acesso à escola tem sido um dos elementos de expressão do processo de sua vinculação a movimentos mais amplos de 
estruturação, consolidação e ampliação da democracia. A democratização da escola se realiza de formas distintas, envolvida nas dinâmicas que caracterizam os diversos contextos sociais, de maneira que, como se sabe, vários países e regiões alcançaram a universalização da escolarização da população infantil, enquanto muitos outros a mantêm como um horizonte a ser buscado. Embora o alargamento do acesso à escola ocorra de modos e em condições bastante diferentes, segundo os vários contextos, tem representado alterações no cotidiano escolar e condicionado mudanças no âmbito das políticas públicas para a educação, com implicações nas orientações formuladas para o processo pedagógico. Em que pesem as várias formas que a democratização da escola vem assumindo, encontram-se três movimentos em comum: ampliação das vagas, elevação dos níveis de escolaridade média e criação de mecanismos para incremento do tempo de permanência das crianças e jovens na escola. Esses esforços, no entanto, vêm se mostrando insuficientes para garantir a todos os alunos trajetórias de sucesso e para fazer da escola um espaço de produção de igualdade de oportunidades, função que historicamente a articula aos projetos de construção de sociedades democráticas.

As experiências mostram que garantir o ingresso e a permanência na escola é condição necessária, mas não suficiente, para produzir uma efetiva democratização do acesso aos conhecimentos socialmente relevantes. Há um aumento expressivo de sujeitos que assumem a condição de aluno, sem, no entanto, uma equivalência na realização das aprendizagens necessárias e/ou validadas, visto que a experiência escolar de muitos é marcada por desempenhos insuficientes e por abandono precoce ${ }^{2}$. Embora amplamente conhecido, vale ressaltar que o fracasso escolar se concentra nas classes populares, que ocupam as periferias do sistema. O sucesso escolar de todos permanece como um desafio que precisa ser superado para que a escola se constitua como um espaço democrático de fato, levando o discurso da democratização a incorporar outro elemento: o compromisso com a qualidade.

Qualidade é uma palavra polissêmica, plástica, que encerra virtualidades e positividades, expressa convergência de preocupações, permitindo a rápida construção de um consenso por criar a idéia de agregação em torno de compromissos comuns. Estas características ocultam o quanto 
suas diferentes acepções guardam possibilidades opostas e contraditórias de organização da escola como projeto social. Diante dos diferentes quadros de insucesso escolar, impossível não se clamar por uma escola de qualidade. Esta relação em que insucesso e qualidade se opõem encobre os diferentes sentidos sociais que cada um destes fenômenos pode ter e as diferentes perspectivas políticas e epistemológicas que configuram sua delimitação e compreensão e o encaminhamento de soluções. A atribuição de valor negativo ao insucesso e a valorização da qualidade - sem maiores detalhamentos e discussões - não deixam ver, por exemplo, que o insucesso muitas vezes resulta de projetos educacionais alinhados à produção de determinadas concepções de qualidade. Essa relação se configura especialmente no projeto de educação formulado nos marcos do modelo neoliberal, que se apropria da idéia de qualidade como justificativa para o estímulo à competição e para a produção de formas de inclusão degradada, rearticulando a dinâmica escolar à manutenção do histórico processo de colonialidade do poder em que são urdidas as relações de subalternização (Mignolo, 2003).

Os desempenhos insuficientes e 0 abandono precoce, 0 fracasso escolar, são narrados como decorrências de processos mais ou menos individualizados e destituídos de qualidade e não como parte de uma concepção excludente de qualidade, necessária a um projeto hegemônico de sociedade que depende da existência de relações de subalternidade. O compromisso com a aprendizagem vai sendo deslocado para o interesse pelo desempenho, levando ao máximo a obsessão pela eficiência, há muito denunciada por Gimeno Sacristán (1997). Os resultados insuficientes servem como referência para as medidas e discursos em torno do fracasso escolar, tendo sempre como objetivo alcançar a qualidade, destituída de sua pluralidade, simplificada, muitas vezes indefinida e constantemente buscada. Esse discurso institui e justifica práticas freqüentemente projetadas numa perspectiva técnica, que isola a atuação pedagógica das múltiplas tensões sociais em que se tecem os processos de inclusão e exclusão de sujeitos e grupos, portanto, articuladas à produção do êxito/fracasso escolar.

A idéia de qualidade unívoca e no singular se insere em um projeto de escola comprometido com a busca de um enquadramento que homogeneíza culturas, valores, conhecimentos e práticas, em um contexto social 
profundamente marcado pelo predomínio da epistemologia positivista. $\bigcirc$ discurso hegemônico sobre a qualidade da educação se entretece aos compromissos da democracia (neo)liberal, tornando opacas as contradições presentes no discurso de defesa da escola de qualidade para todos que institui práticas de classificação, denominação, seleção, exclusão e subalternização de muitos. Imersa nestas relações, proponho como elemento nuclear deste artigo a discussão sobre os sujeitos invisibilizados no projeto de qualidade hegemônico.

\section{Uniformidade do discurso. Pluralidade de sentidos.}

Para a realização do estudo que sustenta a discussão apresentada neste artigo, tratei de cotejar os diagnósticos sobre os fenômenos de abandono e insucesso escolar presentes em diferentes documentos oficiais produzidos em Portugal e pela União Européia, considerando também as propostas formuladas e medidas implementadas com o objetivo de garantir o alcance da qualidade apregoada.

A preocupação com a uniformização dos processos escolares em uma Europa unificada em contexto de globalização e cada vez mais orientada pela competitividade é clara. Assim como é evidente o movimento de definição dos objetivos nacionais para educação e formação por parâmetros delimitados pela União Européia, amparado em um amplo leque de ações, dentre as quais está a realização de um conjunto de exames internacionais sobre os saberes dos estudantes ${ }^{3}$. Dentre eles, o PISA é referência constante nos documentos estudados, evidência de sua relevância para a formulação de políticas públicas com o objetivo de elevar os níveis de desempenho alcançados, em diferentes países.

O PISA, por ser um exame que permite comparar as competências e habilidades desenvolvidas por jovens de 15 anos, independente de seu nível de escolarização, com a finalidade de avaliar a efetividade dos sistemas educacionais, oferece indicadores claros e objetivos das competências que constituem o padrão que deve nortear o percurso escolar. Tais competências se apresentam como necessárias, em um mundo globalizado, o que cobra especial relevância numa Europa cada vez mais unificada e com uma percepção de qualidade padronizada. Por suas características, vincula-se 
fortemente às demandas do mercado de trabalho, de modo que se centra na aplicação cotidiana dos conhecimentos e não em uma abordagem dos conteúdos numa perspectiva escolar. Como se sabe, o PISA é um programa internacional, aplicado em países de diferentes continentes; sua realização em contextos extremamente diferentes expressa seus vínculos com os processos sociais de difusão e consolidação, neste caso, através da padronização de conhecimentos e valores escolares, de uma perspectiva epistemológica e cultural que por ser hegemônica é tratada como universal.

Considerando o contexto da Comunidade Européia, o PISA se mostra relevante para o cumprimento do compromisso com a conformação dos sistemas de ensino dos diferentes países ao modelo europeu, o que ocorre por intermédio de processos diversos, sendo possível verificarem-se traduções múltiplas dessa proposta, em consonância com as questões locais, como, por exemplo, os diferentes anos de escolaridade que os alunos participantes do processo freqüentam, em decorrência dos fluxos escolares heterogêneos. Embora seja previsto que aos 15 anos os alunos estejam além do $9^{\circ}$ ano de escolaridade, no caso português observa-se a seguinte realidade:

Em 2003/2004, dos 94.932 alunos com 15 anos que estavam na escola, apenas $46,3 \%$ freqüentavam $\circ 10^{\circ}$ ano [...] e $3,4 \%$ freqüentavam o $11^{\circ}$ ano. Os restantes estavam distribuídos entre $\circ 2^{\circ}(!)$ e $\circ 9^{\circ}$ anos de escolaridade" (Fernandes, 2007: 11-12).

O nível de escolarização é um dos fatores que tem impacto no desempenho dos estudantes, assim como os resultados alcançados proporcionam indicações diferentes consoantes aos anos de escolaridade a que se direcionam e aos contextos de escolarização que os produzem.

Apesar das diferenças e desigualdades existentes, os resultados dos vários exames internacionais são aceitos como informações fidedignas sobre a qualidade da educação em cada um dos países que deles participam e como legítimos para orientar as estratégias educacionais a se colocar em prática. Também parecem não ser considerados os limites de um exame massivo para medir e comparar resultados obtidos em diferentes contextos, através de instrumentos que sendo traduzidos para diversos idiomas precisam garantir equivalência dos significados em todos eles, além de realizar procedimentos metodológicos idênticos em diferentes contextos (Fernandes, 2007). 
Pode-se inferir que esses limites técnicos não interferem em seu objetivo mais amplo de universalizar um modelo de cultura, de conhecimento e de aprendizagem. A uniformização dos critérios, instrumentos, procedimentos e discursos presentes em processos internacionais de avaliação, cujo sentido articula também os sistemas nacionais, reforça nas práticas escolares a assunção de valores e perspectivas dos grupos hegemônicos, intensificando a generalização e aceitação da racionalidade fundada na ciência moderna, desqualificando e desestruturando outros conhecimentos, valores e formas de conhecer, presentes nos grupos subalternos e postos nas periferias do sistema.

É possível considerar os programas internacionais de avaliação como expressão, no âmbito educacional, daquilo que Boaventura Sousa Santos denomina localismo globalizado, ou seja, os padrões definidos resultam de uma produção local que se apresenta como global para todo o mundo. Porém, neste caso, há um matiz que precisa ser considerado: embora se estruture no âmbito de uma cultura claramente determinada, sua configuração e seu desenvolvimento têm como finalidade alcançar uma escala global. Nesse sentido, a estruturação de sistemas massivos de exame corresponde a uma ação vinculada aos processos de globalização, favoráveis aos grupos hegemônicos, que só se realizam com a produção e manutenção dos pobres e subalternos: a comunicação e a cumplicidade permitidas pela globalização hegemônica assentam numa troca desigual que canibaliza as diferenças em vez de permitir o diálogo entre elas (Sousa Santos, 2006: 79).

A homogeneidade do padrão e a diferenciação dos resultados consolidam as bases para uma distribuição desigual dos sujeitos pelo espectro social, justificada e validada pela aferição dos diferentes níveis de competências. A desigualdade entrelaçada a todo o processo freqüentemente se embaça pelo discurso que se sustenta na preocupação com a qualidade da educação e apresenta a elevação dos níveis de desempenho escolar como estratégia para a criação de igualdade de oportunidades. O detalhamento do relatório de apresentação dos resultados do PISA, composto por dados de cada país em relação às áreas e aos níveis de conhecimentos verificados e pela discussão dos contextos mais adequados à aprendizagem dos estudantes, expressa a presença de uma dimensão formativa em sua configuração (Díaz Barriga, 2006), portanto, vincula sua ação à produção das 
práticas escolares cotidianas. Essa constatação evidencia a função de homogeneização que este exame cumpre, cuja realização demanda cuidados no tratamento dos dados para garantir uma intervenção efetiva nos diferentes contextos escolares. Não é suficiente formular o discurso, é indispensável concretizá-lo através de atos capazes de produzir o reconhecimento do padrão de conhecimentos e processos de aprendizagem e de ensino que orienta este exame como o legítimo, portanto válido e desejável.

A percepção da presença de uma dimensão formativa no processo realizado pelo PISA é um aspecto a que se deve dedicar uma observação cuidadosa ${ }^{4}$ por trazer à tona, um vez mais, os múltiplos e diferentes sentidos que os conceitos e práticas adquirem nos processos cotidianos. A avaliação formativa vem sendo defendida por diferentes autores (Cortesão, 1993; Perrenoud, 2000; Fernandes, 2006; André \& Passos, 1997) como a modalidade mais adequada para a compreensão sobre o que os estudantes sabem e como aprendem, oferecendo informações para ajustar o que e como se ensina aos percursos de aprendizagem, potencializando, assim, a aprendizagem e levando a escola a um trabalho pedagógico de melhor qualidade.

Sem negar a importância da avaliação formativa, é preciso sublinhar sempre que a avaliação (em seus distintos conceitos e funções) é uma atividade eminentemente social, parte de um amplo conjunto de relações. Portanto, dependendo das redes em que se entretece, mesmo a avaliação formativa pode funcionar numa perspectiva predominantemente técnica e vinculada à perspectiva classificatória. Sua ação, como muitas vezes se constata, pode ter como finalidade a melhor preparação dos estudantes para a realização dos diferentes exames a que se submetem, através da reflexão sobre cada processo individual e da regulação da aprendizagem e do ensino balizadas por valores como competitividade, eficiência, rendimento, de modo a articular os princípios da avaliação formativa ao fortalecimento de conteúdos e métodos articulados à dinâmica social de produção de relações de subalternidade. Mesmo assim, a identificação da dimensão formativa no exame citado não pode ser desprezada, já que pode ser apropriada em sua potência e re-significada em seus limites pelas práticas escolares cotidianas.

O conceito de avaliação formativa explicita a ambivalência (Bhabha, 1998) da avaliação, em que a qualidade da educação escolar é 
simultaneamente desejada e negada. A avaliação formativa pode ser integrada a um processo classificatório, ao mesmo tempo em que oferece condições para potencializar as dimensões reflexiva e cooperativa indispensáveis a uma avaliação numa perspectiva emancipatória.

Não basta afirmar a avaliação formativa como um processo melhor para a avaliação dos conhecimentos e para a regulação das aprendizagens. É preciso explorar esse conceito, expressando com clareza as características que deve assumir a fim de participar de um amplo processo de democratização da dinâmica pedagógica, que envolve o aprofundamento da perspectiva crítica no debate sobre as funções da escola, seu currículo e suas práticas cotidianas. A articulação proposta por Afonso (1999) entre avaliação formativa e comunidade indica um sentido que deve ser considerado.

O autor citado toma como referência a relação proposta por Boaventura Sousa Santos entre conhecimento-regulação e conhecimentoemancipação na produção da modernidade, em que há um desequilíbrio favorável à regulação, deixando a emancipação em segundo plano, e a defesa da valorização do conhecimento-emancipação, baseado na intersubjetividade, na reciprocidade, na participação e na solidariedade. Contexto que sinaliza a reinvenção da comunidade como movimento indispensável à perspectiva emancipatória. É na comunidade que Afonso (1999) localiza o processo de afirmação da avaliação formativa como procedimento escolar articulado ao projeto de emancipação.

Defendemos ser possível (e desejável) relocalizar a avaliação formativa dentro de um projeto de educação emancipatória, considerando-a um eixo fundamental na articulação entre o Estado e a comunidade. De fato, a avaliação formativa, sem deixar de estar relacionada com o Estado, como lugar de definição de objetivos educacionais e espaço de cidadania, parece ser a forma de avaliação pedagógica mais congruente com o princípio da comunidade e com o pilar da emancipação. [...] Por outro lado, só a avaliação formativa, como ação pedagógica estruturada na base de relações de reciprocidade, e intersubjetivamente validada (cf. Afonso 1995b), pode promover um novo desequilíbrio no pilar da regulação a favor do pilar da emancipação (Afonso, 1999: 152-153).

A consolidação de uma cultura de avaliação ancorada no exame ${ }^{5}$, que se apropria das diferentes perspectivas produzidas no campo da avaliação, exige a continuidade do debate, enfocando outras perspectivas que ajudem a ressaltar a dimensão ético-política da avaliação, como processo que produz 
fala e silêncio, devendo cuidar especialmente do silêncio como locus ambivalente que se produz como opressão e resistência.

\section{Traduções, produções e traições}

As dinâmicas educacionais, incluindo as ações escolares, se colocam cada vez mais na interface entre as políticas sociais e econômicas, tornando os vínculos entre o projeto de escola e as demandas de natureza econômica evidentes. Especialmente interessante é o modo como essas duas dimensões são apreendidas, muitas vezes nas entrelinhas dos discursos oficiais recolhidos nos documentos analisados. Embora os diagnósticos sejam recorrentes nas referências às relações entre contexto social e resultado escolar, as ações têm como finalidade explícita a inserção da produção nacional num determinado conjunto de relações econômicas, o que permite a compreensão de que o pressuposto está em que o êxito econômico tramado pela produtividade, eficiência e competitividade - conduz à solução dos problemas sociais, o que não se concretiza.

A relação entre o contexto social e as ações educacionais é caracterizada pela ambivalência, conferindo ao social grande força na produção do fracasso e não o reconhecendo como instância significativa na construção de percursos de sucesso, vinculados às decisões, opções e ações individuais. Numa formulação muito resumida, pode-se afirmar que o social é apreendido como fonte de problemas e a economia como articuladora prioritária das soluções. Embora os documentos consultados incorporem um amplo leque de dimensões que compõem o processo educacional, elas são tratadas de modo desarticulado e dentro de generalizações sobre o que o processo educacional deve ser. Não se discute a distribuição desigual do conhecimento, a valoração desigual dos diferentes conhecimentos ou a negação das diferentes epistemologias, tampouco que o fracasso e a desigualdade são próprios do sistema capitalista e do modelo competitivo que fomenta na escola como parte da dinâmica social que produz.

Há, com freqüência, uma associação entre o desempenho de sujeitos de determinados grupos sociais e a produção de índices insatisfatórios de escolarização. Embora o denominado insucesso escolar se concentre nos territórios sociais que ocupam a fronteira entre a inclusão e a exclusão, ou a 
inclusão degradada, a ênfase das políticas públicas recai nas ações individualizadas, vistas como o meio para a elevação dos níveis nacionais de escolarização, dissociando os resultados escolares das redes sócio-culturais em que se tecem as diferentes dimensões da vida. Não se discutem as relações entre os contextos histórico, social e cultural, os diferentes cotidianos escolares e os patamares de escolarização e desempenho estabelecidos como ideais. A elevação da escolarização se associa linearmente ao processo de inclusão social por intermédio da ocupação profissional, ofuscando os múltiplos sentidos que a idéia de inclusão pode adquirir em função dos diferentes contextos em que se realiza e o papel desagregador e excludente da concentração de renda, da redução de postos de trabalho e da precarização do trabalho nas diferentes instâncias.

A relação individual/coletivo é especialmente relevante para a percepção da ambivalência do discurso consolidado sobre a qualidade da escola - a existente ou a almejada. Por um lado, as políticas públicas no campo da educação ressaltam um conjunto alargado de ações individualizadas que buscam produzir uma relação com os conteúdos e práticas pedagógicas, isenta das marcas sócio-culturais dos sujeitos e contextos de desenvolvimento dos processos educacionais. A universalização da escola integra os diferentes procedimentos sociais de universalização do conhecimento hegemônico, considerado verdadeiro, neutro e universalmente válido; o desempenho particulariza os processos e aponta um lugar de inserção do sujeito a partir dessa referência. Por outro lado, os sujeitos que fracassam nos processos educacionais têm sua alteridade desarticulada e são organizados fundamentalmente em duas grandes categorias: a) sujeito em situação de risco - refere risco de abandono escolar, como absenteísmo, falta de cuidados familiares, fracos vínculos com a cultura escolar, pertencimento a minorias lingüísticas, dificuldade de aprendizagem e risco de exclusão social, como o desemprego, a baixa empregabilidade e a proximidade ao crime; b) grupos marginalizados - como imigrantes, minorias étnicas, sujeitos com necessidades educativas especiais e idosos. Estas categorias, demasiadamente amplas, permitem tratar de modo homogêneo grupos imensamente diferentes. Reduzem a diferença entre os grupos, sujeitos e experiências que passam a constituir um conjunto disforme em que a alteridade é substituída pela diversidade de modos de viver a situação de subalternização que o modelo social hegemônico gera. 
A rasura que a categorização produz tenta impedir que a diferença projete o que deveria ser mantido em silêncio e oculto e enuncie a diferença cultural como conflito, negociação e produção, como parte das relações sociais e das disputas de poder. No entanto, as particularidades não deixam de existir, as diferenças permanecem como marcas quase invisíveis que abrem possibilidades de afirmação da existência do que foi negado. As políticas propostas, ou os delineamentos sugeridos, a partir do silenciamento da heterogeneidade, se sustentam em percepções fragmentadas do contexto social e articulam procedimentos coerentes com as exigências do modelo capitalista em vigor. Porém, os discursos amparados na promoção da qualidade da educação e na geração de igualdade de oportunidades colocam à margem do debate os processos sociais e as dinâmicas de poder que produzem a diferença como justificativa para a desigualdade e propõem a negação do outro como percurso para a construção de relações menos injustas. Assim, o outro é sempre marginalizado e excluído, mesmo quando capturado pelo discurso da inclusão. $O$ outro é narrado por discursos que se pretendem globais, embora constituídos por fragmentos, repleto de lacunas e configurados exatamente na ausência do sujeito; a narrativa é tecida como parte das relações assimétricas de poder, destituindo os sujeitos diferentes da condição de narradores de si mesmos.

A relação das diferentes modalidades educacionais com os processos de fracasso escolar e social também está marcada pela ambivalência, apoiada na fragmentação do discurso. A defesa da escolarização como garantia da inclusão social fragmenta os discursos, distanciando a relevância do fracasso escolar como justificativa para a exclusão das situações de exclusão, risco e marginalidade ${ }^{6}$ como justificativas para o insucesso. Nesse sentido, observa-se uma crescente preocupação com a inserção dos sujeitos dos grupos subalternos nos diferentes contextos educacionais, com ênfase na escola, simultaneamente ao desenvolvimento de práticas pedagógicas que dificultam que esses sujeitos vivam o processo educacional como possibilidade de efetiva ampliação de seus saberes e de fortalecimento de sua posição numa perspectiva emancipatória. A persistência do fracasso, mesmo que sob formas renovadas e re-significado, mantém, no silêncio e na invisibilidade, os fios sócio-culturais que o produzem e o papel da escola na solução/produção dos graves problemas sociais: o sucesso escolar não 
garante a inclusão sócio-econômica que, por sua vez, também não é suficiente para resolver os problemas sociais, porém, o fracasso na escola oferece uma explicação convincente para a subalternidade e marginalização. Nesta relação entre escola e sociedade é pertinente lembrar que, como afirma Boaventura Sousa Santos, "a injustiça social assenta na injustiça cognitiva" (2006: 146).

A percepção da ambivalência do discurso que circunscreve a tensão sucesso/insucesso escolar em sua relação com a dinâmica exclusão/inclusão social nos convida a novos olhares sobre a produção escolar de seu próprio fracasso, com a finalidade de encontrar fios que conduzem o êxito e articulálos numa perspectiva contra-hegemônica, em que democracia se conjuga com a emancipação dos sujeitos e grupos subalternos. Esse processo demanda reconsiderar os modos de inserção das margens na reflexão sobre a dinâmica escolar, como uma dinâmica sócio-cultural, e na produção das práticas escolares cotidianas. Pois, as margens são espaços onde circulam sujeitos e culturas negadas, invisibilizadas e silenciadas, o que faz delas uma perspectiva privilegiada para o estudo e construção de processos emancipatórios.

A aproximação ao contexto português, através de documentos oficiais, proporciona elementos para uma melhor visualização dos processos de produção de subalternidade imersos nos discursos de qualificação da escola e dos indivíduos. O Plano Nacional de Prevenção do Abandono Escolar ${ }^{7}$ traz mais dados interessantes para a discussão dos processos sociais de produção e de apagamento das margens.

Um estudo de Benavente et al. (1994) destaca as periferias urbanas e as zonas rurais como as mais atingidas pelo abandono escolar, não só em Portugal, na época, como de forma geral. No mesmo estudo, adiantam-se os filhos de trabalhadores agrícolas, de operários e de artesãos, os filhos de emigrantes e os pertencentes a minorias étnicas como aqueles que mais frequentemente abandonam a Escola (Ministério da EducaçãolMinistério da Segurança Social e do Trabalho, 2004: 31 - em destaque no original).

Ainda que esse quadro tenha sofrido alguma alteração na última década, não foi, sem sombra de dúvidas, completamente alterado. Diante de tantos grupos diferentes envolvidos, é pertinente indagar quais segmentos sociais permanecem na escola incólumes ao abandono escolar. A variedade de origens sociais relacionada ao insucesso escolar deveria colocar em 
discussão as bases em que as práticas escolares cotidianas se constituem. No entanto, se observa a prevalência de indicações referidas à modificação dos sujeitos, ao apagamento de suas experiências e culturas e à inculcação da cultura hegemônica através de conteúdos e processos configurados numa determinada epistemologia. Mantém-se uma narração do outro envolvida pela negação da alteridade e pela busca de (re)produção de um modelo descontextualizado de indivíduo.

Mais uma vez, vemos um grupo bastante variado ser tratado como homogêneo por partilhar a experiência de abandono da escola. A referência ao abandono apaga sua composição heterogênea e proporciona indicação de ações escolares semelhantes, em que pese a diferença dos sujeitos, culturas, experiências e projetos, visando a produção de igualdades de oportunidade via escolarização. Pode-se considerar esse movimento como expressão de um processo social que busca apagar a diferença cultural através da exacerbação da dimensão econômica.

A diferença cultural emerge como noção que possibilita um desdobramento dos processos que legitimam a subalternização dos conhecimentos, legitimando a subjugação dos povos, grupos sociais e sujeitos destituídos de conhecimento, através do suave e democrático processo de oferecimento do único conjunto de conhecimentos socialmente valorizados, consolidando percursos para o exercício da colonialidade ${ }^{8}$ do poder. Legitimar uma única perspectiva epistemológica, um único universo de conhecimentos, um único processo cognitivo, um único conjunto de valores, é um modo de desqualificar tudo o que se diferencia do que se assume socialmente como padrão.

Outra vez nos encontramos com a primazia do conhecimentoregulação (Sousa Santos, 2006) nas práticas escolares cotidianas, atuando no sentido de afastar a possibilidade da escola ser lugar de ampliação de conhecimentos para todos, sublinhando a dimensão plural de conhecer, aprender e ensinar. $O$ conceito de qualidade que sustenta as propostas educacionais está ancorado no rendimento, na competitividade, na hierarquia (portanto na desigualdade) e na eficiência. Sua realização implica na redução dos processos que se pautam na solidariedade, nas relações intersubjetivas de reciprocidade e na participação, também expressa a fragilidade das relações entre o cotidiano escolar e o conhecimento-emancipação (idem). As 
proposições hegemônicas não ajudam a uma reflexão profunda sobre a escola, capaz de indagar em que medida é necessário transformar os seus fundamentos para aprofundar o processo de democratização.

Tais propostas mantêm inalterados os pressupostos excludentes. Uma leitura crítica das entrelinhas dos resultados alcançados e das análises apresentadas nos documentos em discussão atualiza a compreensão de Paulo Freire de que o abandono escolar precoce é uma tradução de um longo processo de expulsão das camadas desfavorecidas da escola. Indica também uma atuação no sentido de culpabilizar a vítima (Collares \& Moysés, 1996): os estudantes que fracassam e suas famílias, negados em sua alteridade, invisibilizados e silenciados para produzir a homogeneidade necessária aos processos de produção, consolidação e explicação das desigualdades.

\section{Teatro de Sombras}

As discussões sobre os procedimentos escolares seguem a tendência encontrada em outras dimensões abordadas nos documentos estudados, o que indica a permanência da diferença cultural como elemento articulador do processo de exclusão. Mantendo a mirada no documento produzido em conjunto pelo Ministério da Educação/Ministério da Segurança Social e do Trabalho (2004), encontram-se outros argumentos importantes para a discussão dos procedimentos escolares nos processos de vinculação da diferenciação à desigualdade. Consolida-se a percepção de que cabe aos estudantes o movimento de adaptação à cultura escolar, como se pode observar na referência à pesquisa feita no Canadá para discutir a produção dos resultados insatisfatórios.

O insucesso escolar revelou-se um risco muito associado à saída precoce da Escola. Cerca de 68\% dos que tiveram insucesso a Francês (língua materna) e cerca de $51 \%$ dos que tiveram insucesso a Matemática em ciclos iniciais acabaram por sair da Escola (Ministério da Educação/Ministério da Segurança Social e do Trabalho; 2004: 34 — grifos no original).

A relação entre repetência e abandono escolar é fartamente conhecida e recorrente em diferentes contextos. O documento se refere a diversos outros estudos em que se encontram elementos que predizem o abandono escolar precoce: todos apontam para a inadequação dos estudantes, de suas famílias e/ou de seus contextos de origem à realidade escolar como o 
elemento articulador do insucesso. Destaco o trecho acima citado não por ser mais um estudo a confirmar a referida relação, mas por apresentar dados que exprimem o domínio das duas linguagens como indispensável para a realização satisfatória do percurso escolar. Ambas são fundamentais na circulação dos conteúdos escolares, portanto, os estudantes incapazes de manejá-las com alguma precisão dificilmente se apropriarão dos conteúdos valorizados na escola e expressarão seus conhecimentos, em decorrência de sua impossibilidade de usar as linguagens e discursos ali reconhecidos e legitimados. Assim, o êxito decorre predominantemente da incorporação da cultura escolar e não do acesso a um universo cada vez mais amplo de conhecimentos e da realização de diferentes aprendizagens.

Não se trata aqui de desprezar a necessidade de se conhecer a língua nacional e a linguagem matemática universalizada, mas de questionar os modos de sua incorporação ao cotidiano escolar. Tratá-los como se fossem compartilhados por todos em medida equivalente ao ingressarem na escola e não como objetos de conhecimento, que vão sendo aprendidos no decorrer do processo de escolarização em estreita ligação com os contextos sócioculturais a que pertencem os estudantes, cria grandes dificuldades àqueles em cujos cotidianos a comunicação e as múltiplas relações quantitativas se estruturam em práticas discursivas diferentes das que conduzem os processos escolares. Se não forem consideradas as diferentes linguagens usadas nos diferentes contextos sociais, fazendo com que alguns cheguem à escola dominando as linguagens fundamentais para as aprendizagens enquanto outros precisam aprendê-las, e se as linguagens que se distinguem da norma forem desqualificadas no cotidiano escolar, o processo pedagógico dificilmente se desligará da dinâmica social de produção de exclusão e subalternidade.

As línguas não são meros fenômenos "culturais" em que os povos encontram sua "identidade", são também o lugar em que o conhecimento está inscrito. E, uma vez que as línguas não são algo que os seres humanos têm, mas algo que os seres humanos são, a colonialidade do poder e do saber veio a gerar a colonialidade do ser (Mignolo, 2003: 632-633).

A percepção daquelas linguagens como pré-requisito para outras aprendizagens escolares esvazia as possibilidades dos estudantes tomaremnas como importantes objetos de conhecimento, portadoras de saberes específicos e modos próprios de contribuição para a articulação de uma 
leitura de mundo mais profunda e complexa. Sendo fundamentais em ambas as acepções, quando consideradas meros veículos de outros conteúdos, esses sim apresentados como relevantes, perdem o interesse, o que acaba por dificultar sua efetiva aprendizagem.

Como se pode apreender na leitura do Plano Tecnológico ${ }^{9}$, nem todos os conhecimentos escolares têm igual valor. A proposta de um ensino básico de elevada qualidade tem como disciplina central Ciências, acompanhada do Português, Matemática e Inglês (Plano Tecnológico). Cabe, uma vez mais, indagar a qualidade buscada quando se relegam a segundo plano Geografia, História, outras Línguas Estrangeiras, Estudo do Meio, Educação Artística e Educação Física. Não se pode deixar de referir a centralidade da perspectiva de neutralidade e objetividade da ciência, cujo desenvolvimento se articula ao progresso, dentro de um conjunto de ações que propõem um sujeito sem raiz, sem história, sem cultura, desterritorializado e fragmentado. Expressão da conformação do currículo escolar à racionalidade moderna. Tal enquadramento também contribui com a produção do insucesso escolar por representar a negação de linguagens, discursos, processos cognitivos, comportamentos, enfim, conhecimentos diferentes dos que estão impressos na cultura hegemônica.

A natureza processual e ambivalente do confronto e exclusão, configurados nas fronteiras institucionais e discursivas, se enuncia, por exemplo, na constatação de que a "retenção parece preceder o abandono escolar" (Ministério da Educação/Ministério da Segurança Social e do Trabalho, 2004: 49 - em destaque no original). Ocorre um longo e complexo processo de desejo e repulsa na relação recíproca entre a escola e determinados grupos de estudantes, bem como destes com o conhecimento escolar, vivido como fortalecimento e negação.

Assumir o conhecimento como neutro e objetivo indica a aprendizagem como um processo harmônico e ordenado. Conhecer, entretanto, envolve tensão, desordem, caos, conflito, luta. O conhecimento, como produção humana, se constitui no âmbito de lutas que se travam em sua produção, manutenção, validade e socialização; lutas que constroem e destroem possibilidades diferentes; lutas que afirmam e subalternizam. 0 conhecimento expõe, explica, oculta, confunde. Nesse mesmo registro podem-se entender os processos de aprendizagem. O conhecimento é plural, 
do mesmo modo que a aprendizagem, ambos são freqüentemente expostos a relações tensas na interação da vida escolar cotidiana com os contextos em que se insere.

A ênfase na perspectiva economicista sublinha as dimensões de atraso e progresso como contraditórias e excludentes. A atribuição de valores opostos a essas duas dimensões nega a relação dialógica e de complementaridade existente entre elas, o que impede a percepção de um conflito entre significados diferentes para a escolarização produzidos em marcos culturais distintos, que também vai se plasmar nas relações dos sujeitos com a escola e com os demais âmbitos da vida cotidiana, como a família e o trabalho. Embora os diferentes significados tenham legitimidade nos contextos em que se produzem, aqueles que entram em conflito com o discurso socialmente dominante sobre a relevância da escola, que exige a submissão às suas normas, são deslegitimados, passando a constituir um alvo a se combater.

A dimensão social do conhecimento e da aprendizagem traz a polifonia como uma de suas principais características, porém, essas múltiplas possibilidades são negadas por um discurso uniforme e normalizador que faz da experiência diferente uma falta, dos vários significados erros, do conflito um processo a ser banido do cotidiano escolar, da incerteza uma fragilidade, do caos uma enfermidade, enfim, das diferentes formas de expressão e experimentação da diferença um distúrbio que deve ser controlado. $O$ discurso unívoco sobre os conteúdos e processos da aprendizagem escolar, sobre seus patamares e valores, sobre suas causas e efeitos, que se evidencia na enunciação da medida como elemento regulador e mobilizador da qualidade, não autoriza a criação a participar do elenco de processos aceitos e estimulados na escola comprometida com desempenho, competitividade e eficiência.

Sem criação - divergente por princípio - não há produção de (novos) conhecimentos, não há aprendizagem em seu sentido profundo; há meramente apropriação superficial e mecânica de conteúdos escolares, freqüentemente fragmentados e desvitalizados. Porém, conhecimento e aprendizagem são produções sociais e conflituosas e essas dimensões rasuradas não deixam de existir e se manifestam de muitas formas, que vão das possibilidades dos sujeitos atribuírem significado à dinâmica escolar e das 
negociações que fazem, muitas vezes passando pela escola sem se deixar afetar muito por ela, até o abandono escolar, o insucesso e o caos produzido por muitos dos que permanecem no sistema educacional. Ambos os movimentos se colocam contra a homogeneidade de parâmetros que sustenta a hierarquia escolar.

A heterogeneidade se mantém como uma das características centrais do cotidiano escolar e também se manifesta por atos realizados por sujeitos desqualificados e expostos em sua negatividade; atos que podem ser traduzidos como expressão da desqualificação e da negatividade que vêm tomando conta da escola como instituição social, gerando dificuldades para sua consolidação como espaço democrático de produção e difusão de conhecimentos e de convivência solidária entre sujeitos diferentes: em seus processos, em suas expectativas, em seus projetos, em seus saberes, em seus pontos de partida e de chegada. Atos que mostram a persistência da diferença no cotidiano escolar, ainda que nas margens do processo pedagógico e pouco utilizada em um sentido favorável a todos. Atos praticados pelos sujeitos que vindos de diferentes contextos e situações sociais são amalgamados nas categorias sujeitos de risco e grupos marginalizados e que justificam o lugar de exclusão que as classes populares continuam ocupando.

Estes não deveriam ser aspectos considerados na reflexão sobre as causas do abandono e do insucesso escolar? Que qualidade se produz quando o êxito é alcançado pela redução do valor da diferença e pela competição, uma vez que é orientado por uma inserção desigual nas hierarquias escolar e social? Que democracia se tece quando o conhecimento se torna instrumento de desqualificação do sujeito e desarticulação da alteridade, sustentando relações de subalternidade e de exercício colonial do poder?

Essas interrogações encontram uma boa perspectiva de discussão com a incorporação da proposição de Boaventura Sousa Santos sobre as "cinco formas sociais de não-existência: o ignorante, o residual, o inferior, o local e o improdutivo" (2006: 97). A validação de uma única racionalidade, vinculada à ciência moderna, atua no sentido de tornar invisível e incompreensível as formas de viver que não se inscrevem nessa perspectiva $^{10}$. Essas formas são a parte desqualificada dos modos de existir 
aos quais se atribui relevância social e se constituem no âmbito de uma razão indolente que não vê alternativas ao modelo atual.

A definição dominante de qualidade da educação e as propostas para o cotidiano escolar dela decorrentes se inscrevem nesse processo de construção de existências compatíveis com a globalização neoliberal. Portanto, iluminam as realidades que adquirem importância social (científicas, avançadas, superiores, globais ou produtivas (cf. Sousa Santos, 2006) como articuladoras do processo educacional e horizonte a ser alcançado pelos indivíduos através da escolarização e buscam eliminar os entraves que a nãoexistência representa. Os processos escolares cotidianos e os exames externos, em suas diferentes modalidades, cumprem relevante papel no apagamento da não-existência como confirmação do que existe, localizando nos indivíduos ou nos grupos que se mostram ignorantes, residuais, inferiores, locais e improdutivos a responsabilidade por sua própria inserção social degradada. Através desse procedimento, se oculta a estreita relação entre os dois conjuntos de realidades e como sua configuração resulta de processos sociais caracterizados por um profundo desperdício da experiência humana.

Nesse contexto, o vínculo entre a escolarização e as demandas do capitalismo se reveste de positividade por mobilizar as realidades válidas $\mathrm{e}$ oferecer as condições para que os indivíduos participem delas. $O$ resultado depende das ações individualizadas, sendo a não-existência apresentada como efeito das impossibilidades dos próprios sujeitos. Os resultados e processos que se diferenciam do conjunto válido não são vistos como portadores de alternativas credíveis às experiências hegemônicas.

Esse modo de compreensão do mundo e de organização das experiências está presente nos documentos oficiais e também está entranhado ao cotidiano escolar. A não-existência funciona permanentemente como uma "ameaça" e a realização ordenada do percurso escolar como a única possibilidade de inscrição em quadros existentes. O insucesso escolar liga-se à não-existência. Observa-se que as duas categorias apresentadas anteriormente que enquadram os sujeitos relacionados ao fracasso escolar estão marcadas claramente pelas idéias de ignorância, vinculada à monocultura do saber e do rigor do saber, de inferioridade, decorrência da lógica da classificação social, projetada a partir da monocultura da 
naturalização das diferenças; e improdutividade, constituída pela lógica produtivista, referenciada na monocultura dos critérios de produtividade capitalistas. De maneira menos evidente, o residual e o local, como características negativas, também atravessam os enquadramentos dos sujeitos: a primeira assenta na monocultura do tempo linear, que faz dos conhecimentos, modos de vida e instituições dominantes nos países centrais a norma que representa o avanço, narrando como atrasado e subdesenvolvido o que não acompanha o padrão; a segunda característica deriva da lógica da escala dominante, em que o global e o universal são as formas centrais da escala válida, de modo que o particular e o local são desqualificados na produção de alternativas.

Entendo que o diálogo com os documentos estudados, a partir da perspectiva aqui apresentada, proporciona mais uma possibilidade de compreensão dos percursos através dos quais diferentes práticas escolares e educacionais se articulam aos processos sociais de produção e manutenção da colonialidade do saber como estratégia da consolidação da colonialidade do poder.

\section{Sujeitos híbridos, cotidianos marginais: novos territórios?}

O projeto educacional em que qualidade se confunde com desempenho cria constrangimentos para a amplificação dos procedimentos escolares comprometidos com sua efetivação como espaço em que os saberes são compartilhados e confrontados, produzindo aprendizagens múltiplas, impossíveis de serem padronizadas, medidas e hierarquizadas. Espaço em que a diferença não seja anúncio e justificativa da desigualdade. Espaço de fortalecimento das classes populares pela aquisição de conhecimentos relevantes para sua histórica luta pela emancipação.

A universalização do acesso à escola no Ensino Básico e a elevação do tempo médio de escolaridade não têm se mostrado suficientes para garantir a todos o conhecimento socialmente relevante, sequer tem conseguido que a maioria dos estudantes alcancem os níveis médios de rendimento, dentro do padrão de conteúdos e desempenho apresentados como desejáveis. Tais resultados não são interpretados pelos que formulam as políticas como insucesso, ou ao menos insuficiência, da própria proposta. Portanto, seguem-se diversos projetos de reformulação de aspectos do 
currículo escolar, buscando-se novas formas de encaminhar a mesma proposição. Esse processo fortalece a dimensão técnica da dinâmica ensinoaprendizagem, desenvolvendo formas contemporâneas de realização da educação bancária, denunciada por Paulo Freire por reduzir as potencialidades do processo pedagógico e por atuar de modo especialmente desfavorável aos sujeitos subalternos, freqüentemente híbridos e instaurados nas margens sociais.

A transformação dos procedimentos escolares tem produzido formas renovadas de insucesso escolar, de tal modo que os avanços obtidos no sentido da universalização do acesso no período de escolaridade obrigatória, a ampliação do tempo médio de escolarização e a expressiva redução das taxas de abandono precoce não são percebidos como conquistas. Sem dúvida são insuficientes, especialmente por não conseguirem desvincular a escola dos processos de exclusão. No entanto, não reconhecer sua positividade em função de novos patamares propostos torna invisível a capacidade de criação e de produção dos sujeitos envolvidos em seu cotidiano, silenciando suas reivindicações no sentido de ampliar a democratização da escola e colocando na sombra os movimentos com a finalidade de articulá-la mais fortemente ao processo de emancipação social.

A concepção produtivista de escola produz análises através de relações lineares que apartam em pólos positivo ou negativo os opostos que conformam sua existência, dificultando a percepção da ambivalência do sentido da escola e das diferentes práticas pedagógicas. Tal percepção mostra-se especialmente relevante quando a diferença cultural é sistematicamente enunciada como causa de fracasso e abandono escolar. As soluções se referem prioritariamente à unificação de padrões e aprofundamento dos vínculos entre escolarização e formação/qualificação para o mercado de trabalho. Os processos de produção cultural, como processos heterogêneos, não são convocados no momento de construção de propostas para a superação dos "problemas" diagnosticados, o que supostamente conduziria a uma interrogação do próprio sentido de problemas.

O discurso hegemônico sobre a qualidade da escola e os percursos propostos para uma escola de qualidade trabalham, cada vez mais, com a configuração de instrumentos e procedimentos que permitem olhares sobre a 
escola, reduzindo as poucas instâncias de participação dos sujeitos que produzem seu cotidiano na reflexão sobre os processos pedagógicos e elaboração de projetos de ação, potencialmente criadores de discursos da escola. O afastamento dos espaços de elaboração dos projetos educacionais dos cotidianos e dos sujeitos que coletivamente vivem a experiência de escolarização impede um conhecimento da realidade escolar, especialmente da que se insere nos espaços marginais, onde se concentram as classes populares, constituídas por sujeitos híbridos que convivem em situação de subalternidade, espaços sociais em que o êxito escolar se mostra constantemente como uma distante promessa.

A aproximação que se faz necessária não é simples, demanda transformações profundas, não meras redefinições procedimentais. No movimento de produção de alternativas, a sociologia das ausências (Sousa Santos, 2006) se apresenta como uma possibilidade interessante, na medida em que busca identificar as experiências produzidas como ausentes, tanto na esfera dos saberes quanto na das práticas, tornando-as presentes e colocando em discussão a concepção de totalidade que as sustenta e as monoculturas que as organizam. Esse processo não será aqui aprofundado, no entanto me parece relevante indicar a existência de outras possibilidades de encaminhamento dos estudos, debates e ações visando à produção de alternativas $^{11}$.

Continuar trabalhando no sentido de uma escola pública de qualidade para todos, fundamentada na permanente busca de novos e mais profundos conhecimentos e não no mero alcance de determinados níveis de desempenho, é preciso. A despeito dos discursos oficiais, amparados na generalização conduzida pela universalização de parâmetros, os sujeitos que fracassam se apropriam de conhecimentos, bem como os produzem; as escolas onde o insucesso se expressa também são espaços de produção de conhecimentos em sua multiplicidade. Talvez o problema central não esteja nos processos e resultados efetivamente vivenciados nos cotidianos escolares, mas nas escalas através dos quais são medidos e nos fundamentos do discurso que os narra. Para potencializar a dimensão emancipatória das práticas e conteúdos escolares é preciso conhecer seu cotidiano, conhecer que existências produzem o que se traduz como nãoexistência, que conhecimentos sustentam o que se percebe como insucesso, 
que sujeitos se constituem nesse processo marcado por silêncio e invisibilidade.

\section{Notas}

1 Trabalho realizado a partir de pesquisa financiada pelo $\mathrm{CNPq} /$ Brasil.

2 Os dados que expressam desempenho insuficiente e abandono precoce são relativos aos contextos sociais em que se produzem. Não obstante a variedade de situações que podem denotá-los, ambos se constituem como indicadores de insucesso escolar para diferentes países.

3 TIMSS (Third International Mathematics and Science Study); IAEP (International Assessment of Educational Progress) e PISA (Program for International Student Assessment).

4 Embora essa questão mereça ser aprofundada, neste artigo se apresenta apenas uma observação inicial, com o objetivo de chamar a atenção a uma discussão relevante que atravessa este estudo.

5 Sobre as relações entre avaliação e exame ver Díaz Barriga (2001).

6 Marginal aqui se refere ao que ocupa as margens: sociais, culturais e escolares.

7 Ministério da Educação/Ministério da Segurança Social e do Trabalho.

8 Para Mignolo (2003), o fim do período colonial como relação política não representou o fim do colonialismo como relação social, mantendo relações de colonialidade: do poder, do conhecer e do ser.

9 "Uma das apostas estratégicas do XVII Governo Constitucional para promover o desenvolvimento sustentado em Portugal é o Plano Tecnológico. O Plano Tecnológico não é mais um diagnóstico. É um plano de acção para levar à prática um conjunto articulado de políticas que visam estimular a criação, difusão, absorção e uso do conhecimento, como alavanca para transformar Portugal numa economia dinâmica e capaz de se afirmar na economia global" (Ministério da Educação (s/d):6).

10 autor distingue cinco lógicas ou modos de produção da não-existência: monocultura do saber e do rigor do saber; monocultura do tempo linear; lógica da classificação social; lógica da escala dominante e lógica produtivista (Sousa Santos, 2006: 95-97).

11 Remeto para outro momento a discussão, numa relação mais direta com o cotidiano escolar, recuperando o ainda-não-saber, que desenvolvi em outros lugares, redimensionado pelo diálogo com a apropriação que Boaventura Sousa Santos faz do conceito de ainda-não proposto por Ernest Bloch.

\section{Referências}

AFONSO, Almerindo J. (1999). Estado, mercado, comunidade e avaliação: esboço para uma rearticulação crítica. Educação e Sociedade, n69, pp. 139-164. 
ANDRÉ, Marli \& PASSOS, Laurizete (1997). Para além do fracasso escolar: uma redefinição das práticas avaliativas. In J. G. Aquino (Org.), Erro e Fracasso na Escola - Alternativas Teóricas e Práticas. São Paulo: Summus, pp. 111-123.

BHABHA, Homi (1998). O Local da Cultura. Belo Horizonte: UFMG.

CERTEAU, Michel de (2002). A Invenção do Cotidiano. Petrópolis: Vozes.

CORTESÃO, Luiza (1993). Avaliação Formativa. Que desafios? Porto: Asa.

COLLARES, Cecília \& MOYSÉS, Maria Aparecida (1996). Preconceitos no Cotidiano Escolar. Ensino e Medicalização. São Paulo: Cortez.

COMMISSION OF THE EUROPEAN COMMUNITIES (2005). Modernising Education and Training: a Vital Contribution to Prosperity and Social Cohesion in Europe. Draft 2006 Joint Progress Report of the Council and the Commission on the Implementation of the "Education \& Training 2010 Work Programme". Brussels: European Community.

Despacho n²351/2007 de 14 de Fevereiro de 2007. Diário da República. 2ª série, № 32 de 14 de Fevereiro de 2007.

DÍAZ BARRIGA, Angel (2006). Las pruebas masivas. análisis de sus diferencias técnicas. Revista Mexicana de Investigación Educativa, n² 29, pp. 583-615.

DÍAZ BARRIGA, Angel (2001). Uma polémica em relação ao exame. In M. T. Esteban (Org.), Avaliação: uma Prática em Busca de Novos Sentidos. Rio de Janeiro: DP\&A, pp. 51-92.

ESTEBAN, Maria Teresa (Org.) (2001). Avaliação: uma Prática em Busca de Novos Sentidos. Rio de Janeiro: DP\&A.

ESTEBAN, Maria Teresa (2002). O Que Sabe Quem Erra? Reflexões sobre Avaliação e Fracasso Escolar. Rio de Janeiro: DP\&A.

FERNANDES, Domingos (2007). Algumas reflexões acerca dos saberes dos alunos em Portugal. Mimeo.

FERNANDES, Domingos (2006). Para uma teoria da avaliação formativa. Revista Portuguesa de Educação, n¹9(2), pp. 21-50.

FOUCAULT, Michel (1979). Microfísica do Poder. Rio de Janeiro: Graal.

GIMENO SACRISTÁN, José (1997). La Pedagogía por Objetivos: Obsesión por la Eficiencia. Madrid: Morata.

GINZBURG, Carlo (1991). Mitos, Emblemas e Sinais. Morfologia e História. São Paulo: Companhia das Letras.

ME.IGE. Ministério da Educação. Inspeção-Geral da Educação (2006). Desempenho Escolar dos Alunos - Nota prévia. [Em linha] [Acedido em 20 de Outubro de 2007, disponível em http://www.ige.min-edu.pt/site_actividadev2/].

MIGNOLO, Walter (2003). Histórias Locais/Projetos Globais. Belo Horizonte: UFMG.

MINISTÉRIO DA EDUCAÇÃO (2007). 50 Medidas de Política para Melhorar a Escola Pública. [Em linha] [Acedido em 01 de novembro de 2007, disponível em ht t p://www.min-edu.pt/np 3 content/ ? newsld=383 \& file Name=medidas_de_politica_op.pdf]. 
MINISTÉRIO DA EDUCAÇÃO (s/d). Plano Tecnológico. Uma Estratégia de Crescimento com base no Conhecimento, Tecnologia e Inovação. Documento de Apresentação. [Em linha] [Acedido em 24 de novembro de 2007, disponível em www.planotecnologico.pt].

MINISTÉRIO DA EDUCAÇÃO/MINISTÉRIO DA SEGURANÇA SOCIAL E DO TRABALHO (2004). Eu não desisto! Relatório do Plano Nacional de Prevenção do Abandono Escolar. [Em linha] [Acedido em 24 de novembro de 2007, disponível em http://www.portugal.gov.pt/].

MORIN, Edgar (1999). Ciência com Consciência. Rio de Janeiro: Bertrand do Brasil. NAJMANOVICH, Denise (2001). O Sujeito Encarnado. Rio de Janeiro: DP\&A.

PERRENOUD, Phillipe (2000). Pedagogia Diferenciada. Das Intenções à Ação. Porto Alegre: Artmed.

SOUSA SANTOS, Boaventura (2006). A Gramática do Tempo. Para uma Nova Cultura Política. Porto: Afrontamento. 


\title{
SILENCING POLYSEMY AND MAKING THE SUBJECTS INVISIBLE: QUESTIONS TO THE DISCOURSE ABOUT THE QUALITY OF EDUCATION
}

\begin{abstract}
The article starts from diagnosis on schooling failures, present in official documents produced in Portugal and by the European Union, to discuss silencing processes and those of invisibility production and subalternity that cross the hegemonic discourse on quality. One of the central ideas in the argumentation made in the article is that to legitimize a single epistemological perspective, a single universe of knowledge, a single set of values, is a way to disqualify what is different from the pattern. Cultural difference is systematically enunciated as the cause of school failure. Despite the discourse supported by the generalization conducted by the universalization of parameters, the subjects that fail appropriate knowledge, as well as generate them and the schools where lack of success is expressed are spaces for the production of multiple knowledge. A public school with quality for all demands knowledge of its day-to-day beyond that what can be perceived through performance evaluation.
\end{abstract}

Keywords

Democratization; Evaluation; School failure; Cultural difference 


\title{
SILENCIAR LA POLISEMIA Y TORNAR LOS SUJETOS INVISIBLES:
} INDAGACIONES AL DISCURSO SOBRE LA CALIDAD DE LA EDUCACIÓN

\begin{abstract}
Resumen
El artículo parte de diagnósticos sobre fracaso escolar, presentes en documentos oficiales producidos en Portugal y por la Unión Europea, para discutir procesos de silenciamiento y producción de invisibilidad y subalternidad que atraviesan el discurso hegemónico respecto a la calidad. Una de las ideas centrales en la argumentación que se teje en el artículo es que legitimar una única perspectiva epistemológica, un único universo de conocimientos, un único conjunto de valores, es un modo de descalificar lo que se muestra diferente del padrón. Se enuncia la diferencia cultural sistemáticamente como causa de fracaso escolar. A pesar de los discursos amparados en la generalización que la universalización de parámetros conduce, los sujetos que fracasan se apropian de conocimientos y asimismo los producen y las escuelas donde el fracaso se expresa son espacios de conocimientos múltiples. Una escuela pública de calidad para todos demanda conocimientos sobre su cotidianidad, más allá de lo que se puede percibir a través de la evaluación del desempeño.
\end{abstract}

Palabras-clave

Democratización; Evaluación; Fracaso escolar; Diferencia cultural

Recebido em Dezembro, 2007 Aceite para publicação em Fevereiro, 2008 